\title{
Higher Levels of Salivary $\alpha$-Amylase Predict Failure of Cessation Efforts in Male Smokers
}

\author{
M. DUŠKOVÁ ${ }^{1 *}$ K. ŠIMŮNKOVÁ ${ }^{1,2 *}$, M. HILL ${ }^{1}$, H. HRUŠKOVIČOVÁ ${ }^{1}$, \\ P. HOSKOVCOVÁ ${ }^{1}$, E. KRÁLÍKOVÁ ${ }^{3}$, L. STÁRKA ${ }^{1}$ \\ *Both authors contributed equally to this work
}

${ }^{1}$ Institute of Endocrinology, Prague, Czech Republic, ${ }^{2}$ Third Department of Medicine, First Faculty of Medicine, Charles University and General University Hospital, Prague, Czech Republic, ${ }^{3}$ The Center for Tobacco Dependence, First Faculty of Medicine and General University Hospital, Prague, Czech Republic

Received September 14, 2009

Accepted February 12, 2010

On-line April 20, 2010

\section{Summary}

The ability to predict the success or failure of smoking cessation efforts will be useful for clinical practice. Stress response is regulated by two primary neuroendocrine systems. Salivary cortisol has been used as a marker for the hypothalamuspituitary-adrenocortical axis and salivary a-amylase as a marker for the sympathetic adrenomedullary system. We studied 62 chronic smokers ( 34 women and 28 men with an average age of $45.2 \pm 12.9$ years). The levels of salivary cortisol and salivary a-amylase were measured during the period of active smoking, and 6 weeks and 24 weeks after quitting. We analyzed the men separately from the women. The men who were unsuccessful in cessation showed significantly higher levels of salivary a-amylase over the entire course of the cessation attempt. Before stopping smoking, salivary cortisol levels were higher among the men who were unsuccessful in smoking cessation. After quitting, there were no differences between this group and the men who were successful in cessation. In women we found no differences between groups of successful and unsuccessful ex-smokers during cessation. In conclusions, increased levels of salivary aamylase before and during smoking cessation may predict failure to quit in men. On the other hand, no advantage was found in predicting the failure to quit in women. The results of our study support previously described gender differences in smoking cessation.

\section{Key words}

Salivary a-amylase • Salivary cortisol • Prediction • Smoking cessation $\bullet$ Stress

\section{Corresponding author}

Michaela Dušková, Institute of Endocrinology, Národní třída 8, 11694 Prague 1, Czech Republic. E-mail: mduskova@endo.cz

\section{Introduction}

Tobacco dependence is considered to be a serious psychosocial problem. A high percentage of adult smokers try to quit, but most of these attempts fail. The ability to predict the success or failure of cessation efforts will be useful for clinical practice.

Quitting smoking is a stressful event. Differences in stress response may predict the success or failure of cessation. Stress response is regulated by two primary neuroendocrine systems, the hypothalamuspituitary-adrenocortical (HPA) system and the sympathetic adrenomedullary (SAM) system. Neuroendocrine markers such as salivary $\alpha$-amylase (sAA) and cortisol in serum or in saliva play an important role in establishing human responses to stressful events.

A disturbing influence of acute stress-induced adrenal activity is less likely in saliva samples, making salivary cortisol values very reliable compared to serum values in stress research (Gröschl 2008).

Salivary cortisol sampling has been used to measure HPA axis activity for some time (Kirschbaum and Hellhammer 1994). Smoking may directly and indirectly influence the functioning of the adrenal gland. 
At the central level, smoking stimulates the release of adrenocorticotropic (ACTH) hormone; this effect is directly proportional to the nicotine dose. At the peripheral level, nicotine increases the effect of ACTH on the adrenal cortex (Steptoe and Ussher 2006). Adrenal androgen secretion is elevated in smokers because of the inhibition of 21- and 11-hydroxylases in the adrenal cortex and the release of dehydroepiandrosterone (DHEA) is higher than the release of cortisol. Elevated ACTH-stimulated levels of androstenedione, 17hydroxyprogesterone and DHEA have been described in male smokers (Hautanen et al. 1993). It has been proposed that serum cortisol directly influences smoking cessation and that changes in serum cortisol following smoking cessation may predict early relapse.

Salivary $\alpha$-amylase concentrations have been suggested as an indirect marker for SAM activity (Rohleder et al. 2004). Studies show a marked increase in sAA concentrations in response to stressful tasks or procedures. Increased levels of sAA have been found during stress (Chatterton et al. 1996). A study of subjects exposed to an academic examination (Bosch et al. 1996) indicated an increase in sAA concentration during the stressful condition, while the salivary flow rate remained unchanged. Nater et al. (2007) reported a distinct diurnal profile pattern of sAA activity with a pronounced decrease within $60 \mathrm{~min}$ after waking and a steady increase of activity in the course of the day. Mixed models have shown a relative independence of diurnal sAA from momentary stress and other factors, but significant associations with chronic stress and mood.

The relation of SAA to the decision-making process has been studied as well. A severe decisionmaking deficit is accompanied by the absence of any changes in salivary cortisol and sAA levels, but slightly reduced decision-making abilities were related to an increase in sAA activity (Labudda et al. 2007).

The aim of our study was thus to evaluate the activity of stress response during smoking cessation. We evaluated the differences in salivary cortisol of chronic smokers and sAA before and after quitting smoking in an attempt to predict the success or failure of smoking cessation.

\section{Methods}

We studied 62 chronic smokers (34 women and 28 men) with an average age of $45.2 \pm 12.9$ years who had sought medical help in quitting smoking at the Center for
Tobacco Addiction Treatment, Third Medical Department, General University Hospital and First Faculty of Medicine Charles University Prague. We obtained complete history of all participants as well as their basic anthropometric data. All participants were healthy; the women did not use any hormonal treatment. The women had mean BMI 24.4 \pm 4.1 and men had mean BMI $26.5 \pm 3.3 \mathrm{~kg} / \mathrm{m}^{2}$. The women began smoking in $17.1 \pm 4.1$ years of age; men began smoking in $13.6 \pm 3.6$ years of age. The women smoked $21.3 \pm 8.9$ cigarettes per day and men smoked $24.6 \pm 10.2$ cigarettes per day. The women tried to quit smoking in mean $2.5 \pm 1.8$ times during the active smoking period; men tried to quit smoking in mean $2.5 \pm 1.9$ times during the active smoking period. The degree of dependence was investigated using the standardized questionnaire FTND (Fagerström Test of Nicotine Dependence - Heatherton et al. 1991), CDS5 and CD12 (Cigarette Dependence Scale - Etter et al. 2003). Samples for sAA and salivary cortisol were collected during the subject's period of active smoking, and 6 weeks and 24 weeks after quitting. We also applied the Minnesota Withdrawal Scale (Hughes and Hatsukami 2008) All the patients involved in the study were strongly nicotine-dependent according to Fagerström Test of Nicotine Dependence (FTND 6 \pm 2 ).

After quitting, all patients used nicotine replacement therapy. The nicotine replacement therapy type and dose were individual according to personal needs. No other pharmacotherapies for tobacco dependence and withdrawal were used. The patients followed the physician's recommendations and received individual behavioral support at the Center for Tobacco Addiction Treatment.

The study included only those patients who were able to quit smoking for longer than 6 weeks. Any relapse did not appear in our patients in the first 6 weeks after cessation of smoking. The study lasted one year. According to guidelines, patients were labeled successful non-smokers after 12 months of abstinence by carbon monoxide (CO) level in expired air (less than $8 \mathrm{ppm}$ ) (Králíková et al. 2005).

The study excluded smokers who were using drug-based therapy involving beta-antagonist and betaagonist activity, which influences sAA activity. When investigated, the patients did not use any drugs that might interfere with the HPA axis. The Local Ethics Committee, Institute of Endocrinology, approved the study and all patients signed informed consent forms before taking part in the study. 
Thirty minutes before the test, the subjects were not allowed to smoke, drink liquids or brush their teeth and they did not have extensive physical activity one day before sampling. Saliva was collected into a plastic device (plain Salivette, Sarsted, Newton, NC, USA); we asked the patients to delicately chew on a cotton tube for $1 \mathrm{~min}$. The cotton tube was then inserted into a plastic tube, which was then capped. None of the saliva samples were contaminated with blood. The saliva was separated from the cotton tube by centrifugation at $1000 \mathrm{rpm}$ for $10 \mathrm{~min}$, after which the saliva samples were frozen and stored in deep freeze ($80^{\circ} \mathrm{C}$ ) until analyzed.

The samples of saliva for measuring sAA were diluted with saline in the ratio of 1:40. Salivary $\alpha$-amylase was measured using the IFCC's enzymatic colorimetric method at $409 \mathrm{~nm}$ (Integra 400+, Roche Diagnostics).

Salivary cortisol was measured using electrochemiluminescence immunoanalysis (Modular E170, Roche Diagnostics).

The relationships between the dependent variable (hormone levels) and the between-subject factor Success of the smoking cessation (eliminating the variability in the dependent variable that is connected with the efficiency of smoking cessation), within-subject factor Stage of the abstinence (eliminating the effect of the stage of the trial), covariate Daytime of the blood collection (eliminating the effect of diurnal rhythms), and subject factor (extracting the inter-individual variability) were simultaneously evaluated using repeated measures ANCOVA model. This model also included success $x$ stage interaction. The differences in basal values were evaluated by two-way ANCOVA model with the factor Success of the smoking cessation and the covariate Daytime of the blood collection. The salivary cortisol profiles in men and women during the trial were evaluated by repeated measures ANCOVA models with the Subject factor, within-subject factor Stage of the abstinence and a covariate Daytime of the blood collection. The original data was transformed by a power transformation (Meloun et al. 2000) to attain Gaussian data distribution and a constant variance in the data and residuals. Non-homogeneities were detected using residual analysis as described elsewhere (Meloun et al. 2004) and excluded from the data set. The proportion of non-homogeneities never exceeded $5 \%$ of the original data. Least significant difference multiple comparisons followed the ANCOVA testing.

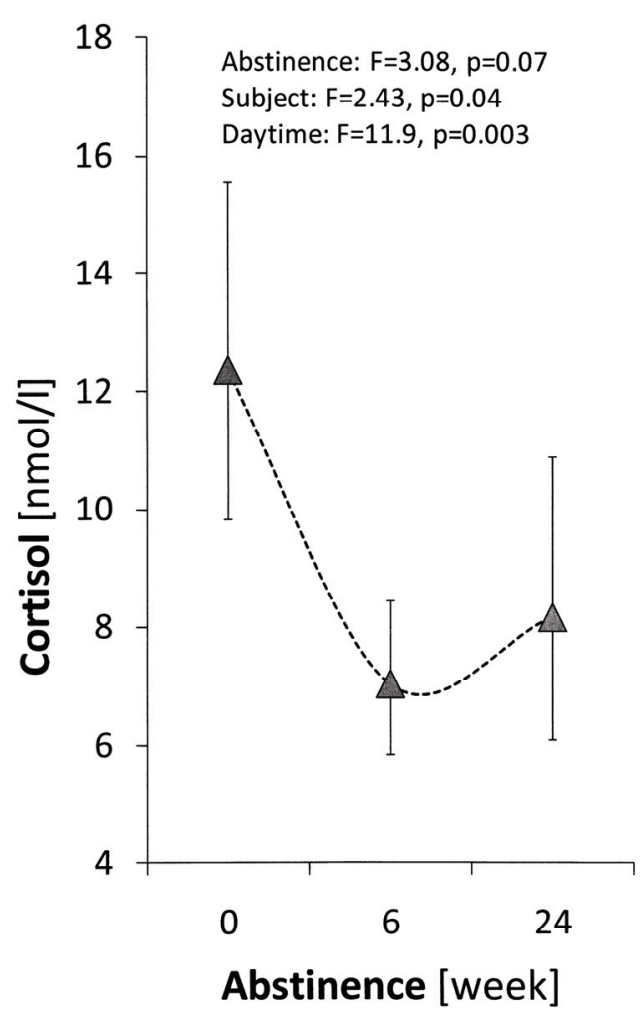

Fig. 1. Changing salivary cortisol levels during the trial in men regardless the effectiveness of the smoking cessation. The triangles with error bars represent the re-transformed mean values with their $95 \%$ confidence intervals. $F$ and $p$ represent F-statistic and $\mathrm{p}$-value for individual factors, respectively.

\section{Results}

The study analyzed the salivary cortisol levels and sAA levels in 62 smokers before and during smoking cessation. The results of men and women were analyzed separately. We examined the results from 34 women (14 successful and 20 unsuccessful in smoking cessation) and 28 men (17 successful and 11 unsuccessful in smoking cessation). There was no difference in success between genders.

The basal levels were compared to analytes investigated subsequently after 6 and 24 weeks of smoking cessation. Each time, the levels of the groups who were successful and unsuccessful in cessation were compared.

In both groups of men, there was a significant and acute decrease in salivary cortisol levels after smoking cessation (Fig. 1). The women, on the other hand, showed only a slight but insignificant decrease in salivary cortisol after smoking cessation. Neither the men nor the women showed any change in sAA concentrations over the course of cessation. There were no gender differences in the basal levels of sAA. Basal salivary cortisol levels also showed no sex differences. 


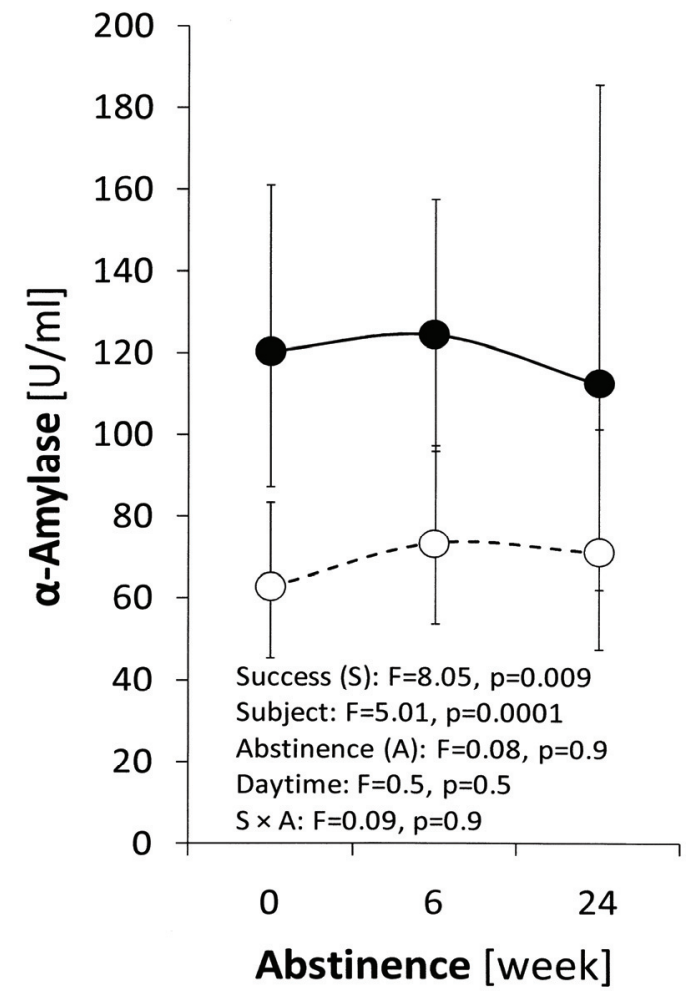

Fig. 2. Salivary a-amylase levels during the trial in men. The empty circles represent the re-transformed mean values for the groups of men with successful outcome of the smoking cessation, while full circles correspond to the re-transformed mean values for the participants who failed to stop smoking. The error bars represent $95 \%$ confidence intervals for the group means. $F$ and $p$ symbolize F-statistic and $\mathrm{p}$-value for individual factors (interaction).

However, we found that men who were unsuccessful in smoking cessation already had higher levels of sAA before beginning their cessation attempt and that these high levels continued during the entire cessation attempt until failure (Fig. 2). In addition, unsuccessful men manifested insignificantly higher basal salivary cortisol levels as compared to men who were successful in smoking cessation $(p=0.13$, data not shown).

We found no differences in salivary cortisol and sAA between women who were successful or unsuccessful in smoking cessation.

Neither the dependence tests nor the Minnesota craving scale were of any value for predicting success in men or women.

\section{Discussion}

Salivary $\alpha$-amylase levels have been proposed as a marker for the activity of the sympathetic nervous system. Cortisol in serum or saliva appears to be a valid measure for HPA axis activity.

The results of studies on cortisol levels in smokers are mixed. In some reports, acute increases in circulating cortisol were observed after smoking, but other studies found no changes. These contradictory findings resulted from different study protocols and methods for evaluating cortisol levels. Cortisol has a diurnal profile, and it has been suggested that the salivary cortisol awakening response and release of salivary cortisol during the day is greater in smokers as compared with non-smokers (Steptoe and Ussher 2006). Smokers have also been found to have greater serum cortisol production in samples taken during the day (Field et al. 1994).

Badrick et al. (2007) found increased salivary cortisol in current smokers. During the day, the production of salivary cortisol was higher in smokers as compared with non-smokers; cortisol levels also depended on the number of cigarettes smoked. No differences were observed between ex-smokers and individuals who had never smoked, suggesting that smoking has a short-term effect on the neuroendocrine system.

Serum cortisol levels decreased significantly in people who give up smoking, especially during the early period of cessation (Frederick et al. 1998). Chronic smokers showed enhanced levels of salivary cortisol secretion as compared with non-smokers. Smoking cessation was associated with decreased salivary cortisol levels; in the short-term, smoking cessation did not correct the diminished adrenocortical responses to stress caused by chronic smoking (Berlin 2009). We found significantly higher levels of salivary cortisol during the smoking period as compared to the period after quitting. These findings agree with the literature.

Smokers with lower levels of salivary cortisol suffered from cessation of smoking more than smokers with higher levels (Ussher et al. 2006). In our study, we did not find any correlation between craving and salivary cortisol level.

The influence of smoking on sAA levels has been measured by several previous studies, without obtaining uniform results. We found no changes in preand post-quitting sAA levels in men and women. Prior to stopping smoking, there were significantly higher levels of sAA in men who failed in cessation, but later during the cessation attempt these men had only non significant elevation of sAA levels compared to successful men. Higher levels of sAA could predict unsuccessful smoking 
cessation in men. We did not find a change in sAA levels in women.

Callegari and Lami (1984) have observed that cigarette smokers exhibit a reduction in serum S-type isoamylase that correlated well with the significant reduction of sAA activity in their study. Weiner et al. (2008) found an inhibition of sAA following the exposure to cigarette smoke and the external addition of purified aldehydes known to be present in cigarette smoke. Their results indicated that the significant decrease in sAA amylase activity was due to unsaturated aldehydes, which probably reacted through their double bond with the thiol group of proteins via the Michael addition reaction (Weiner et al. 2008). Maier et al. (1991) found increased sAA activity after intravenous nicotine infusion $(20 \mu \mathrm{g} / \mathrm{kg})$. Jauniaux et al. (1999) observed higher $\alpha$-amylase activity in fetal plasma of smoking mothers. Granger et al. (2007) studied the effects of environmental tobacco exposure, examining smoking and non-smoking mothers and their children. They found higher salivary cortisol and lower sAA activity in smoking mothers than in controls. Their results showed no associations between maternal smoking behavior, infant cotinine levels and infant sAA activity or salivary cortisol level (Granger et al. 2007). Nater et al. (2007) found that the number of cigarettes smoked prior to salivary measure did not significantly influence sAA. Smoking status had no effect on sAA activity. Our results are well correlated with this finding that smoking has no influence on sAA activity.

Nicotine dependence level according to the FTND score mostly correlates with quit rates (Groman et al. 2009), but not in all studies (Raherison et al. 2005, Nerin et al. 2004), as in our case. The explanation could be that all the participants had similar and high score of dependence.

The reported data of gender differences in failing to quit smoking are confusing. Kotz et al. (2009) provided a cross-sectional household survey of 3,767 smokers. They found that the factors associated with the increased use of aids for cessation were: female sex, older age, more cigarettes smoked per day, and planning a cessation attempt.

Santos et al. (2008) studied a group of 203 smokers who sought professional assistance for smoking cessation. They identified aspects (such as being female and having been diagnosed with depression) that are known predictors for treatment failure.

Weinberger et al. (2009) examined the interaction of gender and lifetime psychiatric status on experience of nicotine withdrawal using retrospective data from National Comorbidity Survey $(n=816)$. The report described that women showed a stronger association between major depression and recurrent withdrawal symptoms as well as between post-traumatic stress disorder and smoking relapse in order to alleviate withdrawal symptoms.

Croghan et al. (2009) did not evaluate gender differences in their study, their retrospective analysis of clinical data from smokers who received individualized tobacco dependence treatment. Nerin et al. (2007) observed no gender differences in the probability of abstinence in their study of smoking cessation therapy at a specialized unit.

Menstrual phase may play a role in the relationship between craving, salivary cortisol concentration and risk for relapse (Allen et al. 2009). We did not observe the relationship between salivary cortisol concentration and risk for relapse in women.

Al'Absi et al. (2002) tested enhanced psychophysiological response after 18 hours of abstinence, which produced significant withdrawal symptoms in all participants. Women reported a greater desire to smoke than men. We did not find any difference in men and women in reporting desire to smoke. Men had higher salivary cortisol levels than women, and both men and women showed the expected decline in salivary cortisol levels with the time (al'Absi et al. 2002). These findings correlate with our results on decreased salivary cortisol levels after cessation.

Two further studies by al'Absi and coworkers demonstrated that a steep decline in salivary cortisol concentration during early abstinence and hyporesponsiveness to stress predict a shorter period of relapse. They showed that hormonal associations with smoking relapse tend to be more consistent in men. This result correlates with our study. The studies also found that the intensity of withdrawal symptoms tend to be a consistent predictor of smoking relapse in women (al'Absi et al. 2002, al'Absi 2006), but we did not observe this trend.

In the study by Ceballos and al'Absi (2006) salivary cortisol levels and the ratio of salivary cortisol to dehydroepiandrosterone sulfate did not differ significantly between individuals (all probands were women), who were successful in smoking cessation and those who failed in the course of tobacco withdrawal, as we observed in our study.

We conclude that salivary $\alpha$-amylase 
concentrations at the beginning of cessation might be a predictive marker for successful smoking cessation in men. These findings support the evidence that the characteristics of smoking and the biochemical marker differ between men and women. Additional study with more frequent measurements and combinations of stress markers will be needed in order to find a predictive model for successful smoking cessation.

\section{Conflict of Interest}

There is no conflict of interest.

\section{Acknowledgements}

We thank the study participants and our excellent research nurses especially Vladěna Felbrová. The study was supported by the grant no. NR 9055-4 of the IGA MZ CR.

\section{References}

AL'ABSI M: Hypothalamic-pituitary-adrenocortical responses to psychological stress and risk for smoking relapse. Int J Psychophysiol 59: 218-227, 2006.

AL'ABSI M, AMUNRUD T, WITTMERS LE: Psycholophysiological effects of nicotine abstinence and behavioral challenges in habitual smokers. Pharmacol Biochem Behav 72: 707-716, 2002.

ALLEN AM, ALLEN SS, WIDENMIER J, AL'ABSI M: Patterns of cortisol and craving by menstrual phase in women attempting to quit smoking. Addict Behav 34: 632-635, 2009.

BADRICK E, KIRSCHBAUM C, KUMARI M: The relationship between smoking status and cortisol secretion. J. Clin Endocrinol Metab 92: 819-824, 2007.

BERLIN I.: Endocrine and metabolic effects of smoking cessation. Curr Med Res Opin 25: 527-534, 2009.

BOSCH JA, BRAND HS, LIGTENBERG TJ, BERMOND B, HOOGSTRATEN J, NIEUW AMERONGEN AV: Psychological stress as a determinant of protein levels and salivary-induced aggregation of Streptococcus gordonii in human whole saliva. Psychosom Med 58: 374-382, 1996.

CEBALlOS NA, AL'ABSI M.: Dehydroepiandrosterone sulfate, cortisol, mood state and smoking cessation: relationship to relapse status at 4-week follow-up. Pharmacol Biochem Behav 85: 23-28, 2006.

CALLEGARI C, LAMI F: Cigarette smoking and salivary amylase activity. Gut 25: 909, 1984.

CHATTERTON RT Jr, VOGELSONG KM, LU YC, ELLMAN AB, HUDGENS GA: Salivary $\alpha$-amylase as measure of endogenous adrenergic activity. Clin Physiol 16: 433-448, 1996.

CROGHAN IT, EBBERT JO, HURT RD, HAYS JT, DALE LC, WARNER N, SCHROEDER DR: Gender differences among smokers receiving interventions for tobacco dependence in a medical setting. Addict Behav 34: 61-67, 2009.

ETTER JF, LE HOUEZEC J, PERNEGER TV: A self-administered questionnaire to measure dependence on cigarettes: the cigarette dependence scale. Neuropsychopharmacology 28: 359-370, 2003.

FIELD AE, COLDITZ GS, WILLETT, LONGCOPE C, MCKINLAY JB: The relations of smoking, age, relative weight, and dietary intake to serum adrenal steroids, sex hormones, and sex hormone binding globulin in middle-aged men. J Clin Endocrinol Metab 79: 1310-1316, 1994.

FREDERICK SL, REUS VI, GINSBERG D, HALL SM, MUNOZ RF, ELLMAN G: Cortisol and response to dexamethasone as predictors of withdrawal distress and abstinence success in smokers. Biol Psychiatry 43 : 525-530, 1998.

GRANGER DA, BLAIR C, WILLOUGHBY M, KIVLIGHAN KT, HIBEL LC, FORTUNATO CK, WIEGAND LE, FAMILY LIFE PROJECT INVESTIGATORS: Individual differences in salivary cortisol and $\alpha$-amylase in mothers and their infants: relation to tobacco smoke exposure. Dev Psychobiol 49: 692-701, 2007.

GRÖSCHL M: Current status of salivary hormone analysis. Clin Chem 54: 1759-1769, 2008.

GROMAN E, RIEMERTH A, STEINER-RINGL A, VEITSMEIER I, KROAT A, KROAT U, BERNHARD G: Outpatient smoking cessation: a report on 3,260 cases. Wien Med Wochenschr 159: 40-46, 2009.

HAUTANEN A, MÄNTTÄRI M, KUPARI M, SARNA S, MANNINEN V, FRICK MH, ADLERCREUTZ H: Cigarette smoking is associated with elevated adrenal androgen response to adrenocorticotropin. $J$ Steroid Biochem Mol Biol 46: 245-251, 1993.

HEATHERTON TF, KOZLOWSKI LT, FRECKER RC, FAGERSTRÖM KO: The Fagerström test for nicotine dependence: a revision of the Fagerström tolerance questionnaire. Br J Addiction 86: 1119-1127, 1991. 
HUGHES JR, HATSUKAMI D: Background on the Minnesota Withdrawal Scale-Revised (MNWS-R). 2008 www.uvm.edu/ hbpl

JAUNIAUX E, GULBIS B, ACHARYA G, GERLO E: Fetal amino acid and enzyme levels with maternal smoking. Obstet Gynecol 93: 680-683, 1999.

KIRSCHBAUM C, HELLHAMMER DH: Salivary cortisol in psychoneuroendocrine research: recent developments and applications. Psychoneuroendocrinology 19: 313-333, 1994.

KOTZ D, FIDLER J, WEST R: Factors associated with use od aids to cessation in English smokers. Addiction 104: 1403-1410, 2009.

KRÁLÍKOVÁ E, BÝMA S, CÍFKOVÁ R, ČEŠKA R, DVOŘÁK V, HAMANOVÁ J, HORKÝ K, HRADEC J, KELLER O, KONŠTACKÝ S, KOS S, KOSTŘICA R, KUNEŠOVÁ M, KVAPIL M, LANGROVÁ K, MAYER O, PETRŮ V, POPOV P, RABOCH J, ROSOLOVÁ H, ROZTOČIL K, SUCHARDA P, VORLÍCEK J, WIDIMSKÝ J: Recommendations for the treatment of tobacco dependence. (in Czech) Čas Lék Čes 144: 327-333, 2005.

LABUDDA K, WOLF OT, MARKOWITSCH HJ, BRAND M: Decision-making and neuroendocrine responses in pathological gamblers. Psychiatry Res 153: 233-243, 2007.

MAIER H, JARCYK L, SCHERER G, BORN IA: Effects of acute nicotine administration on the function od the human parotid gland. Laryngorhinootologie 70: 24-26, 1991.

MELOUN N., HILL M., MILITKÝ J, KUPKA K: Transformation in the PC-aided biochemical data analysis. Clin Chem Lab Med 38: 553-559, 2000.

MELOUN N, HILL M, MILITKÝ J, VRBÍKOVÁ J, STANICKÁ S, ŠKRHA J: New methodology of influential point detection in regression model building for the prediction of metabolic clearance rate of glucose. Clin Chem Lab Med 42: 311-322, 2004.

NATER UM, ROHLEDER N, SCHOLTZ W, EHLERT U, KIRSCHBAUM C: Determinants of the diurnal course of salivary a-amylase. Psychoneuroendocrinology 32: 392-401, 2007.

NERIN I, NOVELLA P, CRUCELAEGUI A, BEAMONTE A, SOBRADIEL N, GARGALLO P: Predictors of success at 6-month follow-up for smokers treated at a smoking cessation clinic. Arch Bronconeumol 40: 558-562, 2004.

NERIN I, NOVELLA P, BEAMONTE A, GARGALLO P, JIMENEZ-MURO A, MARQUETA A: Results of smoking cessation therapy in a specialist unit. Arch Bronconeumol 43: 669-673, 2007.

PERKINS KA, SCOTT J: Sex differences in long-term smoking cessation rates due to nicotine patch. Nicotine Tob Res 10: $1245-1250,2008$.

RAHERISON C, MARJARY A, VALPROMY B, PREVOT S, FOSSOUX H, TAYTARD A: Evaluation of smoking cessation success in adults. Respir Med 99: 1303-1310, 2005.

ROHLEDER N, NATER UM, WOLF JM, EHLERT U, KIRSCHBAUM C: Psychosocial stress-induced activation of salivary $\alpha$-amylase: an indicator of sympathetic activity? Ann NY Acad Sci 1032: 258-263, 2004.

SANTOS SR, GONÇALVES MS, LEITÃO FILHO FS, JARDIM JR: Profile of smokers seeking a smoking cessation program. J Bras Pneumol 34: 695-701, 2008.

STEPTOE A, USSHER M: Smoking, cortisol and nicotine. Int J Psychophysiol 59: 228-235, 2006.

USSHER M, WEST R, EVANS P, STEPTOE A, MCEWEN A, CLOW A, HUCKLEBRIDGE F: Reduction in cortisol after smoking cessation among users of nicotine patches. Psychosom Med 68: 299-306, 2006.

WEINBERGER AH, MACIEJEWSKI PK, MCKEE SA, REUTENAUER EL, MAZURE CM: Gender differences in associations between lifetime alcohol, depression, panic disorder, and posttraumatic stress disorder and tobacco withdrawal. Am J Addict 18: 140-147, 2009.

WEINER D, LEVY Y, KHANKIN EV, REZNICK AZ: Inhibition of salivary amylase activity by cigarette smoke aldehydes. J Physiol Pharmacol 59: 727-737, 2008. 